\title{
Depolarization of Cochlear Outer Hair Cells Evokes Active Hair Bundle Motion by Two Mechanisms
}

\author{
Helen J. Kennedy, ${ }^{1}$ Michael G. Evans, ${ }^{2}$ Andrew C. Crawford, ${ }^{3}$ and Robert Fettiplace ${ }^{1}$ \\ ${ }^{1}$ Department of Physiology, University of Wisconsin Medical School, Madison, Wisconsin 53706, ${ }^{2}$ MacKay Institute of Communication and Neuroscience, \\ School of Life Sciences, Keele University, Staffs ST5 5BG, United Kingdom, and ³Department of Physiology, Cambridge University, Cambridge CB2 3EG, \\ United Kingdom
}

There is current debate about the origin of mechanical amplification whereby outer hair cells generate force to augment the sensitivity and frequency selectivity of the mammalian cochlea. To distinguish contributions to force production from the mechanotransducer (MET) channels and somatic motility, we have measured hair bundle motion during depolarization of individual outer hair cells in isolated rat cochleas. Depolarization evoked rapid positive bundle deflections that were reduced by perfusion with the MET channel blocker dihydrostreptomycin, with no effect on the nonlinear capacitance that is a manifestation of prestin-driven somatic motility. However, the movements were also diminished by Na salicylate and depended on the intracellular anion, properties implying involvement of the prestin motor. Furthermore, depolarization of one outer hair cell caused motion of neighboring hair bundles, indicating overall motion of the reticular lamina. Depolarization of solitary outer hair cells caused cell-length changes whose voltage-activation range depended on the intracellular anion but were insensitive to dihydrostreptomycin. These results imply that both the MET channels and the somatic motor participate in hair bundle motion evoked by depolarization. It is conceivable that the two processes can interact, a signal from the MET channels being capable of modulating the activity of the prestin motor.

Key words: anion; dihydrostreptomycin; cochlea; calcium; mechanosensory; hair cell

\section{Introduction}

The frequency discrimination and sensitivity of the mammalian cochlea are underpinned by outer hair cells (OHCs), generating force to mechanically amplify sound-induced vibrations of the cochlear partition (Dallos, 1992). Two mechanisms of force generation have been proposed: contractions of the $\mathrm{OHC}$ body and active motion of the hair bundle. Substantial evidence favors the former process, somatic contractility, as the predominant force generator (Brownell et al., 1985; Ashmore, 1987), driven by a voltage-dependent conformational change in prestin (Zheng et al., 2000). Prestin is concentrated in the hair cell lateral membrane and derives its voltage dependence from the binding of intracellular anions, especially chloride (Oliver et al., 2001). Targeted deletion of prestin results in loss of $\mathrm{OHC}$ contractility and a $>100$-fold reduction in auditory sensitivity (Liberman et al., 2003). Although the properties of somatic motility have been characterized extensively in isolated $\mathrm{OHCs}$, which probably lack mechanotransduction, there is little direct information about its contribution in the intact organ of Corti in which the hair cell mechanotransducer (MET) channels are fully functional.

Received Sept. 8, 2005; revised Jan. 15, 2006; accepted Jan. 16, 2006.

This work was supported by National Institutes on Deafness and Other Communicative Disorders Grant R01 DC 01362 (R.F.).

Correspondence should be addressed to Robert Fettiplace, 185 Medical Sciences Building, 1300 University Avenue, Madison, WI 53706. E-mail: fettiplace@physiology.wisc.edu.

H. Kennedy's present address: Department of Physiology, School of Medical Sciences, University of Bristol, Bristol BS8 1TD, UK.

DOI:10.1523/JNEUROSCI.3808-05.2006

Copyright $\odot 2006$ Society for Neuroscience $\quad$ 0270-6474/06/262757-10\$15.00/0
Additional force generation could be provided by the hair bundle linked to gating of the MET channels (Crawford and Fettiplace, 1985; Howard and Hudspeth, 1987; Martin and Hudspeth, 1999). Active hair bundle movements have been well documented in nonmammalian hair cells, in which they have been correlated with two phases of MET channel adaptation (Fettiplace and Ricci, 2003). Slow adaptation occurs over tens of milliseconds and may be implemented through a nonmuscle myosin (Gillespie and Cyr, 2004), whereas fast adaptation stems directly from channel reclosure and can operate on a submillisecond timescale (Fettiplace and Ricci, 2003). In the channel mechanism, positive deflection of the bundle opens MET channels and increases stereociliary $\mathrm{Ca}^{2+}$, which recloses the channels and causes the bundle to spring back, opposing the stimulus. This has been referred to as a "twitch" or recoil, and it has sufficient speed to operate at acoustic frequencies (Benser et al., 1996; Ricci et al., 2000). Because the driving force on $\mathrm{Ca}^{2+}$ influx decreases at positive membrane potentials, active hair bundle motion can also be elicited by depolarizations that reduce stereociliary $\mathrm{Ca}^{2+}$ (Assad et al., 1989; Ricci et al., 2000). Fast adaptation is not restricted to nonmammals, has been demonstrated in mammalian $\mathrm{OHCs}$ (Kros et al., 1992; Kennedy et al., 2003), and is associated with force generation by hair bundles (Kennedy et al., 2005) as it is in nonmammals.

Electrical stimuli applied across the organ of Corti in isolated preparations have been shown to produce deformation of the cochlear partition (Mammano and Ashmore, 1993) and motion of the hair bundles of inner hair cells (Chan and Hudspeth, 2005). 
However, in neither work was the electrical stimulus confined to an individual hair cell. Here we have measured motion of the hair bundles evoked by depolarization of single OHCs, which might be expected to recruit both active hair bundle motility and somatic contractility. Our aims were to assess the relative contributions of the two processes to $\mathrm{OHC}$ force generation and to understand how they might interact.

\section{Materials and Methods}

Preparations. Experiments were performed on outer hair cells from the apical turn of the organ of Corti of Sprague Dawley rats between postnatal day 6 (P6) and P16 using methods reported previously (Kennedy et al., 2003). Animals were anesthetized with halothane and killed by decapitation using methods approved by the Animal Care Committee of the University of Wisconsin. Experiments to image hair bundles used isolated cochlear coils, whereas somatic contractility was characterized in solitary hair cells obtained by enzymatic dissociation of the organ of Corti. Cochlear coils were isolated from P6-P14 rats as follows: after removing the bone from the apical and middle turns, the stria vascularis was unpeeled and, after a $15 \mathrm{~min}$ incubation in saline containing 50 $\mu \mathrm{g} / \mathrm{ml}$ bacterial subtilisin protease (type XXIV; Sigma, St. Louis, MO), the tectorial membrane was removed. The excised apical and middle turns were fixed in the experimental chamber with strands of dental floss and viewed through a $40 \times$ long working distance water-immersion objective [numerical aperture (NA), 0.8] on a Zeiss (Oberkochen, Germany) Axioskop FS microscope. The chamber was perfused with artificial perilymph composed of the following (in $\mathrm{mm}$ ): $154 \mathrm{NaCl}, 6 \mathrm{KCl}, 1.5$ $\mathrm{CaCl}_{2}, 2 \mathrm{Na}$-pyruvate, 10 glucose, and $10 \mathrm{Na}$-HEPES, $\mathrm{pH}$ 7.4. The apical surface of the organ of Corti was separately perfused through a $100 \mu \mathrm{m}$ pipette with a perilymph-like solution containing normal $\mathrm{CaCl}_{2}(1.5$ mM) or reduced $\mathrm{CaCl}_{2}$. Two different low- $\mathrm{Ca}^{2+}$ solutions were used, containing 0.1 or $0.03 \mathrm{~mm}$. The higher $\mathrm{Ca}^{2+}$ concentration also included $1.0 \mathrm{mM} \mathrm{MgCl}_{2}$. The lower $\mathrm{Ca}^{2+}$ concentration is similar to that in rat endolymph (Bosher and Warren, 1978).

Solitary outer hair cells were obtained by incubating segments of the organ of Corti from P10-P16 rats in saline containing $0.5 \mathrm{mg} / \mathrm{ml}$ type IV collagenase (Sigma) for $10 \mathrm{~min}$ and then triturating three times through a $100 \mu$ l pipette tip. Dissociated outer hair cells were transferred to a chamber mounted on the stage of a Zeiss Axiovert 100 inverted microscope and viewed though a $40 \times$ objective (NA 0.8 ) and $2 \times$ optovar. The experimental chamber was perfused with an extracellular solution composed of the following (in mM): $150 \mathrm{NaCl}, 6 \mathrm{KCl}, 1.5 \mathrm{mM} \mathrm{CaCl}_{2}, 1.0 \mathrm{~mm}$ $\mathrm{MgCl}_{2}, 2 \mathrm{Na}$-pyruvate, 8 glucose, and $10 \mathrm{Na}$-HEPES, $\mathrm{pH}$ 7.4. In some experiments, the chloride salts of $\mathrm{Na}^{+}$and $\mathrm{K}^{+}$in the extracellular perfusate was replaced with gluconate, which does not permeate chloride channels. In other experiments to block somatic motility, $10 \mathrm{~mm} \mathrm{Na}$ salicylate was added to the extracellular solution with equimolar reduction in $\mathrm{NaCl}$. All experiments were performed at room temperature (19$23^{\circ} \mathrm{C}$ ). To break tip links and block mechanotransduction, a submicromolar $\mathrm{Ca}^{2+}$ solution (composition: $140 \mathrm{~mm} \mathrm{NaCl}, 6 \mathrm{~mm} \mathrm{KCl}, 2.5 \mathrm{~mm}$ $\mathrm{CaCl}_{2}, 5 \mathrm{~mm} \mathrm{Cs}_{4} \mathrm{BAPTA}, 8 \mathrm{~mm}$ glucose, and $10 \mathrm{~mm}$ Na-HEPES, pH 7.4, and $0.2 \mu \mathrm{M}$ free $\mathrm{Ca}^{2+}$ ) was pressure ejected on the a hair bundle from a pipette as described previously (Ricci et al., 2003).

Electrical recording. Outer hair cells were whole-cell voltage clamped with borosilicate patch electrodes connected to an Axopatch 200A (Molecular Devices, Palo Alto, CA) or a List EPC7 amplifier (ALA Scientific Instruments, Westbury, NY). Patch electrodes were introduced through a small hole made in the reticular lamina and were advanced along the organ of Corti to record from a cell several cells along from the hole to ensure that the reticular lamina was intact at the recording site. Recordings in isolated coils were made from first or second row outer hair cells at the beginning of the apical turn, $\sim 0.8$ of the distance along the basilar membrane from the base. From the place-frequency map in adult rats, this recording site corresponds to a characteristic frequency of $\sim 4 \mathrm{kHz}$ (Müller, 1991). Optimizing light piping by the hair bundle was attained by fixing the cochlea so that the bundle was oriented vertically along the optical axis. With the hair bundle vertical, the radial tilt of the cell body was less than $\sim 20^{\circ}$ with respect to the optical axis, equivalent to a dis- placement of the base of a $30 \mu \mathrm{m}$ cell abneurally by one cell diameter $(\sim 10 \mu \mathrm{m})$ relative to its apex. Patch pipettes were filled with two types of intracellular solution with different major anions, chloride or sulfate. The chloride solution contained the following (in mM): $142 \mathrm{CsCl}, 3.5$ $\mathrm{MgCl}_{2}, 1$ EGTA, $5 \mathrm{Na}_{2} \mathrm{ATP}, 0.5 \mathrm{Na}_{2} \mathrm{GTP}$, and 10 Cs-HEPES, pH 7.2 (osmolarity of $\sim 300 \mathrm{mOsm}$ ). For the sulfate solution, $\mathrm{CsCl}$ was replaced with $110 \mathrm{~mm} \mathrm{Cs}_{2} \mathrm{SO}_{4}$ and $\mathrm{MgCl}_{2}$ with $\mathrm{MgSO}_{4}$, giving an intracellular solution of similar osmolarity to the chloride solution. With the sulfate solution, the shank and part of the body of the patch pipette were filled with the sulfate intracellular solution, but the electrode was backfilled with a chloride-containing solution to maintain the reversibility of the $\mathrm{Ag} / \mathrm{AgCl}$ electrode and thereby reduce offset potentials. Patch pipettes with resistances of 2.5-5 M $\Omega$ were used, having recording time constants of between 30 and $60 \mu$ s with up to $70 \%$ series-resistance compensation. The shank of the patch pipette was coated with wax to reduce stray capacitance. Membrane potentials were corrected for the residual series resistance of the electrode and for the junction potentials between the extracellular and intracellular solution of $4 \mathrm{mV}(\mathrm{CsCl})$ and $12 \mathrm{mV}$ $\left(\mathrm{Cs}_{2} \mathrm{SO}_{4}\right)$. For the resistances of patch pipettes used, the time constant of exchange of the pipette solution with that of the cell interior is expected to be $<1$ min (Tucker and Fettiplace, 1996). All recordings lasted for at least $15 \mathrm{~min}$, during which time total exchange of the pipette solution (e.g., sulfate replacement for chloride) with the cell interior would have been achieved.

Outer hair cells in isolated coils were mechanically stimulated as described previously (Kennedy et al., 2003). Hair bundles were deflected by the axial motion of a glass pipette waxed to and driven by a piezoelectric stack actuator (model P-802; Physik Instrumente, Karlsruhe, Germany). The tip of the probe was fire polished to $\sim 3 \mu \mathrm{m}$ in diameter to fit the "V"-shaped stereociliary bundle of the outer hair cell. The actuator was driven with voltage steps shaped with an eight-pole Bessel filter set at a corner frequency of $2-4 \mathrm{kHz}$. Membrane current and voltage and photodiode voltage were digitized with a Power 1401 at $150 \mathrm{kHz}$ (Cambridge Electronics Design, Cambridge, UK) and analyzed with IgorPro version 4.00 (WaveMetrics, Lake Oswego, OR). All records are averages of 10 stimulus presentations, and, unless otherwise indicated, the results are expressed as mean \pm 1 SEM. In all experiments on hair cells in the intact coil, MET currents were first recorded to ensure that transduction was fully functional, and the experiment was continued if the size of the MET current exceeded $0.3 \mathrm{nA}$. The probe was then pulled back from the hair bundle and bundle movements measured in response to depolarizing voltage steps. Transduction was often checked later in the experiment by advancing the probe back onto the bundle, and the measurements were discontinued if the MET current amplitude dropped below the criterion value. Recordings were usually maintained for $>15 \mathrm{~min}$, over which period the MET current was stable with no more than a $20 \%$ reduction in amplitude. Maximum MET currents ranged from 0.3 to $1.0 \mathrm{nA}$, within the range of those reported previously (Kennedy et al., 2003).

The charge movements occurring during prestin activation were quantified by integrating the initial capacitive transient at the start of the voltage step (Tunstall et al., 1995). This integration was performed for the initial 1-2 ms after the voltage step in two separate ways: (1) by fitting an exponential to the onset of the ionic current, subtracting this fit from the total current, and integrating the resulting transient; and (2) by measuring the amplitude of the capacity transient and dividing it by the time constant of decay of the transient (see Fig. 1C). Both methods gave similar answers. To accurately measure the charge movements attributable to prestin, it was important that the linear cell capacitance was compensated at a membrane potential at which there was little prestin activation, i.e., at which there was negligible nonlinear charge movement. In situations in which this was important, linear capacitance compensation was performed using $-20 \mathrm{mV}$ steps from a holding potential of -100 to $-120 \mathrm{mV}$. Using the Boltzmann fits to the voltage dependence of somatic contractions (see Fig. 9) as a measure of the true voltage dependence of prestin activation (and hence nonlinear capacitance), we estimate that nulling the linear capacitance at $-120 \mathrm{mV}$ introduces an error of no more than $\sim 6 \%$ in the magnitude of the nonlinear capacitance.

Imaging of hair cell motion. Motion of free-standing hair bundles in isolated coils was detected by projecting the image of the tip of the 
A
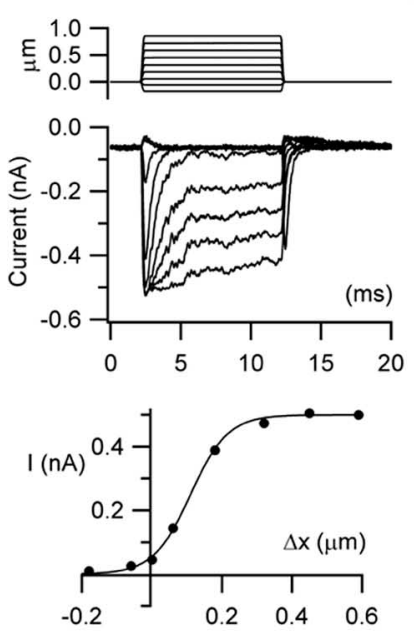

$\mathrm{B}$
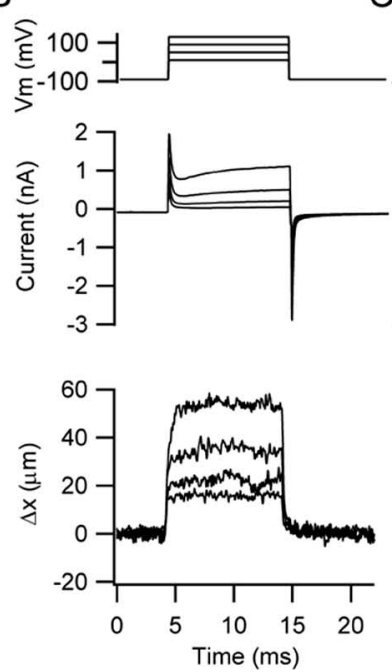

C
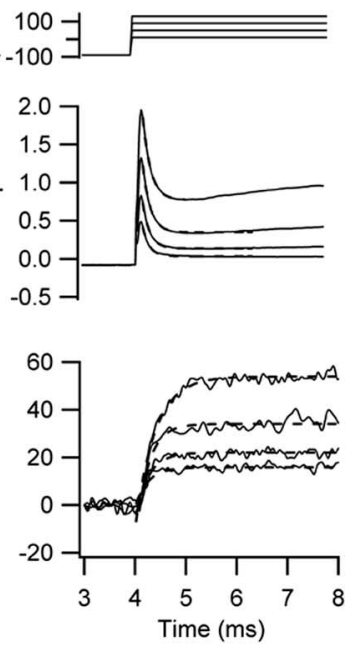

Figure 1. Mechanotransducer currents and hair bundle movements in an outer hair cell. $\boldsymbol{A}$, Imposed deflections of the hair bundle elicit MET currents with pronounced fast adaptation, which has a time constant for small responses, 0.28 ms. The relationship between peak current and bundle displacement is shown (filled circles), which has been fit with a single Boltzmann equation: $I=I_{\max } /\left(1+\exp \left(\left(V_{0.5}-V\right) / V_{\epsilon}\right)\right)^{-1}$, with $I_{\max }$ of $0.5 \mathrm{nA}, V_{0.5}$ of $0.11 \mu \mathrm{m}$, and $V_{\epsilon}$ of $0.053 \mu \mathrm{m}$. Holding potential, $-84 \mathrm{mV}$. B, Membrane currents and hair bundle movements in the excitatory direction (toward the tip of the $V$ ) for depolarizing voltage steps from a holding potential of $-90 \mathrm{mV}$. Note the large-capacity transients indicative of the charge movements associated with prestin activation. $\boldsymbol{C}, 0$ nset of currents and movements shown on a faster timescale. Superimposed on the records are exponential fits with time constants of $0.14,0.14,0.16$, and $0.16 \mathrm{~ms}$ for the decay of the capacity transient for increasing voltage step and $0.26,0.26,0.25$, and 0.39 ms for onset of the movement. P10 rat, $\mathrm{Cs}_{2} \mathrm{SO}_{4}$ intracellular solution.

V-shaped bundle onto a pair of photodiodes (LD 2-5; Centronics, Newbury Park, CA) at $800 \times$ total magnification. The differential photocurrent was filtered at $5 \mathrm{kHz}$. At the apical cochlear location studied, hair bundles have a maximum height of $\sim 5 \mu \mathrm{m}$ (Roth and Bruns, 1992). The photodiodes were mounted on a piezoelectric bimorph, deflections of which were used to calibrate the photocurrent throughout the recording (Kennedy et al., 2005). Voltage steps to the photodiode bimorph were delivered at the end of each sweep to evoke a lateral movement of the photodiodes equivalent to $14 \mathrm{~nm}$ in the object plane and in a direction away from the tip of the $\mathrm{V}$ of the bundle. The voltage steps were filtered with an eight-pole Bessel filter at $70 \mathrm{~Hz}$. Because small drifts in the positioning of the hair bundle on the diodes could alter the size or polarity of the differential photocurrent, it was important that the photocurrent be calibrated for each stimulus presentation. Although the size of the photodiode signal depended critically on focusing at the top of the hair bundle, we do not think that the measured motion reflected a change in focus because the calibration was unaffected. Thus, if the calibrating voltage steps to the photodiode bimorph were also presented during the response (rather than after it), the calibration signal was identical. Any focus change during the response would have diminished the calibration signal. All measurements of bundle movements in the isolated cochlear coil were performed on OHCs with robust MET currents of maximum amplitude $>0.3 \mathrm{nA}$. Contractions of solitary outer hair cells in response to voltage steps were measured by projecting the image of the apical edge of the cell onto a photodiode pair at a total magnification of $330 \times$. The photodiodes could be aligned so that their long axis was perpendicular to longitudinal axis of the outer hair cell. The photocurrent was calibrated as for the bundle motion in isolated coils but by manual displacement of the photodiodes through a known distance in the image plane.

\section{Results}

\section{Depolarization and the hair bundle motor}

MET currents recorded in outer hair cells were graded with hair bundle displacements of a few tenths of a micrometer and showed fast onset and adaptation in response to a step stimulus (Kennedy et al., 2003). Depolarization to positive membrane potentials produced a negative shift in the current-displacement relationship and slowed adaptation. These two effects most likely stem from reduction in stereociliary $\mathrm{Ca}^{2+}$ because they recapitulate most of the consequences of lowering extracellular $\mathrm{Ca}^{2+}$ in both mammals (Kennedy et al., 2003) and nonmammals (Crawford et al., 1989; Ricci et al., 2000). As in nonmammals, depolarization also elicited positive deflections of the freestanding hair bundle (Fig. 1). Here a positive movement is defined as one toward the tip of the $V$ that is excitatory and opens MET channels. The magnitude and polarity of the bundle displacement were ascertained from calibration pulses presented at the end of each sweep (see Materials and Methods). The magnitude of the signal from the hair bundle depended critically on the microscope focus, but its polarity was always opposite to that of the calibration pulse, which was equivalent to a negative displacement away from the tip of the hair bundle. Hair bundle deflection increased monotonically with the size of the depolarization, in some cells attaining a maximal excursion of $60-80 \mathrm{~nm}$ at +80 $\mathrm{mV}$. The depolarization-evoked bundle motion comprised a significant fraction of the operating range of the MET channels, which was $\sim 200 \mathrm{~nm}$ in Figure 1. The displacement of the hair bundle developed rapidly, reaching steady state in $<1 \mathrm{~ms}$, and was sustained for the length of voltage pulses $10-20 \mathrm{~ms}$ in duration. In Figure 1, the bundle displacement had an onset time constant of $0.26 \mathrm{~ms}$ for the smaller responses, slower than the time constant of the capacity transient $(0.16 \mathrm{~ms})$ but similar to the time constant of fast adaptation $(0.28 \mathrm{~ms})$. In other cells, the onset time constant ranged from 0.15 to $0.45 \mathrm{~ms}$, which, depending on the exact mechanism, could be limited by either MET channel gating or the mechanical events (hair bundle relaxation or reticular lamina deformation).

To test for the involvement of the MET channels in the hair bundle motion, cells were perfused with $0.2 \mathrm{~mm}$ dihydrostreptomycin (DHS), which is known to block these channels in both nonmammalian (Kroese et al., 1989) and mammalian (Kros et al., 1992) hair cells. The experiments were performed with 0.1 $\mathrm{mm}$ extracellular $\mathrm{Ca}^{2+}$ to potentiate the action of DHS (Ricci, $2002)$. In the low- $\mathrm{Ca}^{2+}$ solution, a fraction $(0.34 \pm 0.05 ; n=3)$ of the MET channels was activated at rest, manifested as a standing inward current at the holding potential $(-84 \mathrm{mV})$. Application of DHS diminished the standing current and also reversibly reduced or abolished the depolarization-induced displacement of the hair bundle (Fig. 2A,B). Similar results were seen in eight P7-P10 rat OHCs in which the maximal hair bundle displacement was $47 \pm 8 \mathrm{~nm}$ for mean depolarization to $+65 \mathrm{mV}$, and the amount of movement blocked by DHS was $34 \pm 6 \mathrm{~nm}(72 \%)$. The blocking effect of DHS on the bundle motion occurred without any effect on the nonlinear capacitance determined by integrating the onset current transient (Fig. 2C). The nonlinear capacitance is thought to reflect the charge movements occurring during prestin activation (Ashmore, 1989; Santos-Sacchi, 1991).

MET channel currents can also be blocked by exposure to submicromolar $\mathrm{Ca}^{2+}$ (Crawford et al., 1991), a maneuver thought to act by severing the tip links (Assad et al., 1991). A brief 
pulse of submicromolar $\mathrm{Ca}^{2+}$, buffered with BAPTA, reduced the amplitude of bundle motion (Fig. $3 A$ ) in a previously transducing cell. The reduction occurred without significant effect on the bundle image, as indicated by the fact that the photodiode current for the $14 \mathrm{~nm}$ calibration was unchanged by the maneuver. Similar to the DHS experiment, there was also no effect of the manipulation on the amplitude of the initial capacity transient. Both DHS and BAPTA experiments suggest that a component of the active hair bundle motion evoked by depolarization is linked to gating of the MET channels.

\section{Effects of $\mathrm{Ca}^{2+}$ on bundle movements}

If depolarization-evoked motion of the hair bundle is caused by a decrease in $\mathrm{Ca}^{2+}$ influx secondary to reduced driving force on the ion, it should also be susceptible to varying extracellular $\mathrm{Ca}^{2+}$. Changes in intracellular $\mathrm{Ca}^{2+}$ are expected to affect both types of motor output, whether arising from MET adaptation (Ricci et al., 2000) or somatic contractility (Frolenkov et al., 2000), although the effects may differ depending on the mechanism. Reduction in external $\mathrm{Ca}^{2+}$ from 1.5 to $0.03 \mathrm{~mm}$ reversibly increased the size of the movements by $50-100 \%$. This was correlated with an increase in the amount of outward current activated at $+80 \mathrm{mV}$. In the example shown (Fig. 3B), the movement in response to depolarization to $+80 \mathrm{mV}$ was $\sim 1$.6-fold larger in $0.03 \mathrm{mM} \mathrm{Ca}^{2+}(58 \mathrm{~nm})$ compared with that in $1.5 \mathrm{mM} \mathrm{Ca}^{2+}$ (37 $\mathrm{nm})$. Likewise, the size of the net outward current at $+80 \mathrm{mV}$ was increased by the same factor, $0.44 \mathrm{nA}$ in $0.03 \mathrm{mM} \mathrm{Ca}^{2+}$ compared with $0.28 \mathrm{nA}$ in $1.5 \mathrm{mM} \mathrm{Ca}^{2+}$. In seven outer hair cells from P7-P11 rats, the maximum depolarization-induced hair bundle displacement increased by a factor of $1.78 \pm 0.31$ in $0.03 \mathrm{~mm}$, and the current increased by $1.61 \pm 0.13$. The increase in the bundle movements may stem from a shift in the $\mathrm{Ca}^{2+}$ equilibrium potential to a less positive membrane potential, so that depolarization reduces intracellular $\mathrm{Ca}^{2+}$ to lower levels. Lowering $\mathrm{Ca}^{2+}$ is also expected to increase both the single MET channel conductance (caused by relief of block) and the probability of opening of the channels (caused by a negative shift in the channel-activation relationship) (Ricci et al., 2003).

The activation range depends on the intracellular anion Because depolarization will also cause $\mathrm{OHC}$ contractions that may translate into movements of the hair bundle, other procedures were adopted to reduce or eliminate contamination by somatic contractions. In most of the initial experiments, mea$0.77 \mathrm{nA}$.
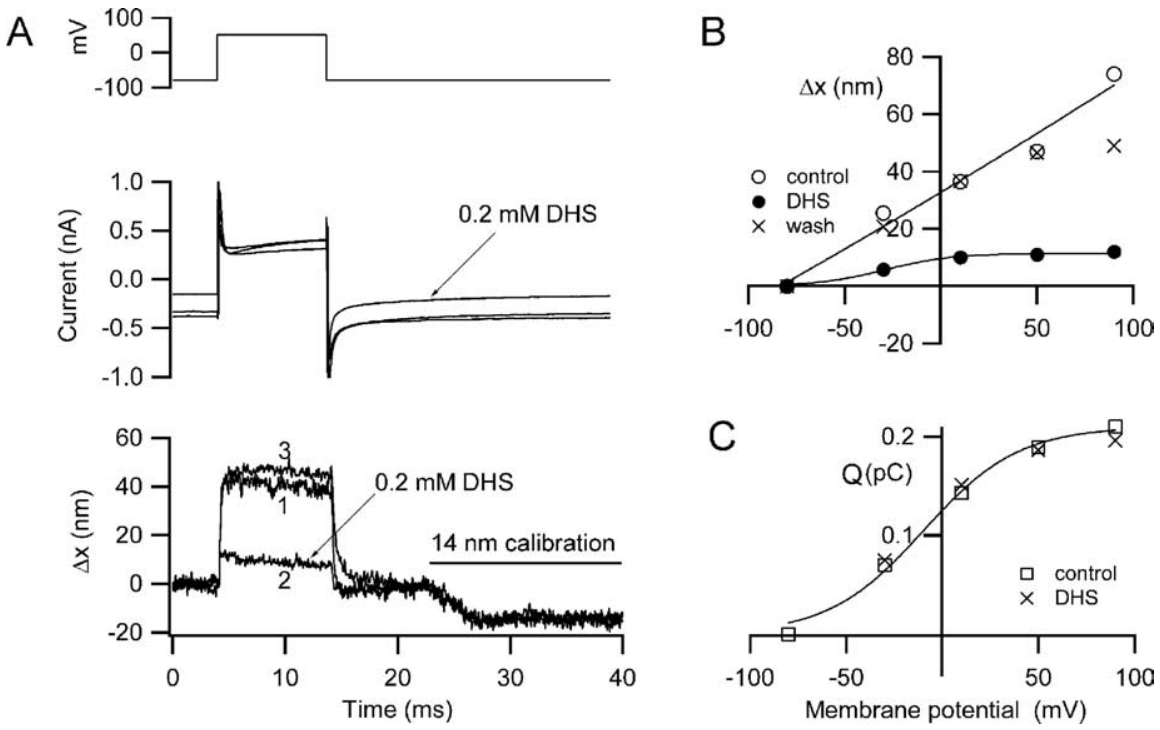

Figure 2. Depolarization-induced hair bundle motion and its block by dihydrostreptomycin. $\boldsymbol{A}$, Membrane currents (middle) and hair bundle movements, $\Delta x$, (bottom) for depolarization to $+50 \mathrm{mV}$ before (1), during (2), and after (3) recovery from application of $0.2 \mathrm{~mm}$ DHS. DHS reduces the maximum movement and also blocks part of the current turned on at the holding potential $(-84 \mathrm{mV})$. For all $\Delta x$ traces, movement toward the tip of the $V$ is denoted as positive, and the negative deflections at the end of the traces is a $14 \mathrm{~nm}$ calibration signal. $\boldsymbol{B}$, Voltage dependence of the movements $(\Delta x)$ before, during, and after DHS application. $\boldsymbol{C}$, Voltage dependence of charge movement $(Q)$ before and during DHS perfusion. The charge movement $(Q)$, calculated from the current transients at the onset of the depolarizing step, reflects activation of the prestin motor and is unaffected by DHS. Bathing solution contains $0.1 \mathrm{~mm} \mathrm{Ca}^{2+}$ and $1 \mathrm{~mm} \mathrm{Mg}^{2+} . \mathrm{P} 9$ rat, $\mathrm{CsCl}$ intracellular, maximum MET current of
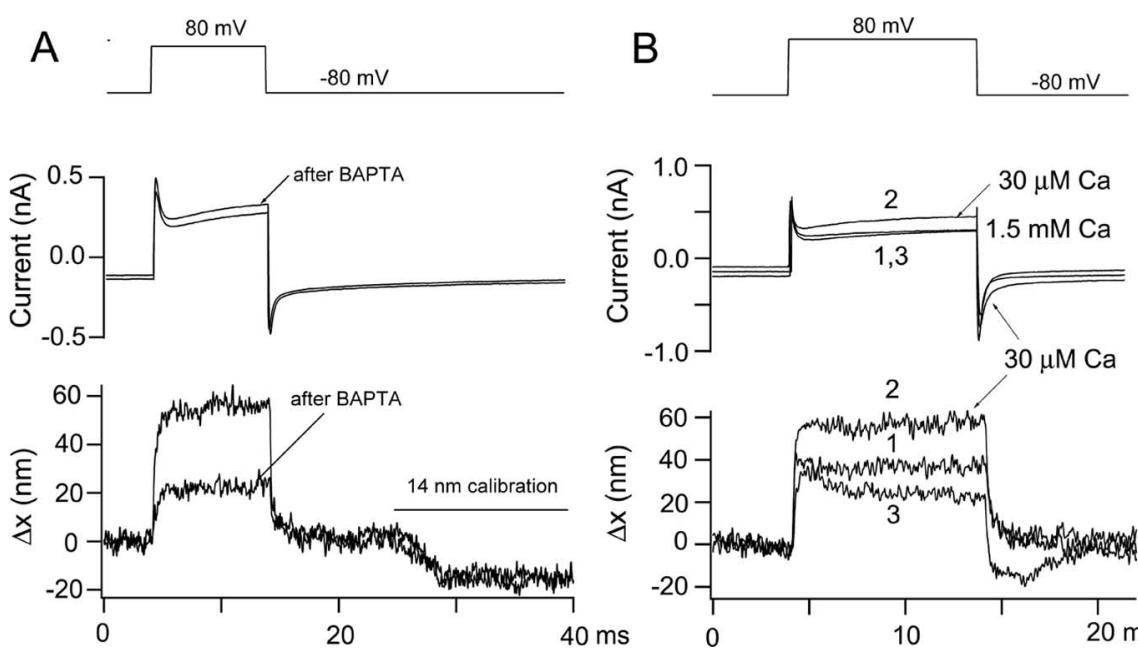

Figure 3. Effects of $\mathrm{Ca}^{2+}$ on hair bundle motion. $\boldsymbol{A}$, Membrane currents and bundle movements for depolarizing voltage steps to +80 mV before and immediately after pressure ejection of submicromolar $\mathrm{Ca}^{2+}$ buffered with 5 mM BAPTA. The manipulation produced a two-thirds decrease in the motion without effect on the capacity transients. The movements have not been scaled for the size of the calibration response, and the change in photodiode current for the $14 \mathrm{~nm}$ calibration was virtually identical before and after BAPTA, suggesting no drift or change in the bundle image after BAPTA application. P10 rat, $\mathrm{Cs}_{2} \mathrm{SO}_{4}$ intracellular, maximum MET current of $0.35 \mathrm{nA}$. The MET current had declined to $<0.1 \mathrm{nA}$ after the treatment. $\boldsymbol{B}$, Membrane currents and bundle movements for depolarization to $+80 \mathrm{mV}$ before (1), during (2), and after (3) lowering the extracellular $\mathrm{Ca}^{2+}$ concentration from $1.5 \mathrm{~mm}$ to $30 \mu \mathrm{m}$. Note that $\mathrm{Ca}^{2+}$ reduction increases the sizes of both movement and current. $\mathrm{P}^{2} \mathrm{rat}_{1} \mathrm{Cs}_{2} \mathrm{SO}_{4}$ intracellular, maximum MET current of $0.71 \mathrm{nA}$.

surements were made with cesium sulfate as the major constituent of the intracellular solution because this has been reported to abolish prestin activation (Oliver et al., 2001). As will be demonstrated later, this is not totally effective. Comparison of the chloride and sulfate intracellular solutions did not reveal any major differences in peak hair bundle displacement for depolarizations to $+100 \mathrm{mV}$. Mean values measured in $1.5 \mathrm{~mm}$ external $\mathrm{Ca}^{2+}$ in 


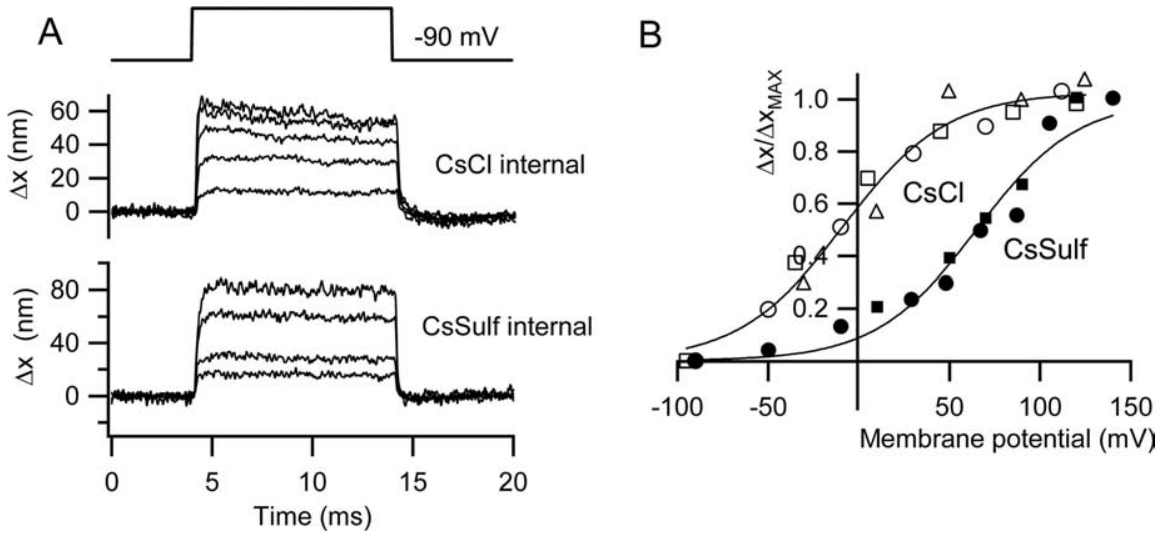

Figure 4. Effects of intracellular anion on hair bundle motion. $\boldsymbol{A}$, Families of bundle movements $(\Delta x)$ recorded in two outer hair cells with different intracellular solutions, $\mathrm{CsCl}$ (top) and $\mathrm{Cs}_{2} \mathrm{SO}_{4}$ (bottom), for a range of membrane potentials from -90 to +110 $\mathrm{mV}(\mathrm{CsCl})$ and -90 to $+140 \mathrm{mV}\left(\mathrm{Cs}_{2} \mathrm{SO}_{4}\right)$. Timing of voltage pulse is shown above. $\boldsymbol{B}$, Plots of bundle movements $(\Delta x)$ normalized to the maximum motion $\left(\Delta x_{\max }\right)$ versus membrane potential for three cells with CsCl intracellular (open symbols) and two cells with $\mathrm{Cs}_{2} \mathrm{SO}_{4}$ intracellular (filled symbols). Note that the steepness of the voltage dependence is similar, but the results in $\mathrm{Cs}_{2} \mathrm{SO}_{4}$ are shifted $\sim 75 \mathrm{mV}$ positive relative to those with $\mathrm{CSCl}$. Smooth curves are fits to the following: $\Delta x / \Delta x_{\max }=(1+\exp$ $\left.\left(\left(V_{0.5}-V\right) / V_{\epsilon}\right)\right)^{-1}$, where $V_{0.5}$ and $V_{\epsilon}$ were -9 and $29 \mathrm{mV}$, respectively, for chloride and +65 and $28 \mathrm{mV}$ for sulfate.

$\mathrm{P} 8-\mathrm{P} 14$ rats were $38 \pm 4 \mathrm{~nm}\left(n=21 ; \mathrm{Cs}_{2} \mathrm{SO}_{4}\right)$ and $36 \pm 4 \mathrm{~nm}$ $(n=23 ; \mathrm{CsCl})$. The mean saturating MET currents with these two intracellular solutions were $0.67 \pm 0.05 \mathrm{nA}\left(\mathrm{Cs}_{2} \mathrm{SO}_{4}\right)$ and $0.73 \pm 0.04 \mathrm{nA}(\mathrm{CsCl})$. Nevertheless, in those cells in which measurements were taken over a sufficiently wide voltage range, the movements were activated at more negative membrane potentials when using chloride-containing electrodes. Figure $4 B$ shows collected results of activation curves for hair bundle displacements, normalized to the maximum values, in three cells with chloride and two cells with sulfate intracellular solution. With chloride electrodes, the movements usually showed saturation with depolarization, but this was rarely evident with sulfate electrodes. The results in Figure $4 B$ were fitted with a Boltzmann function, relating the movement $\Delta x$ (scaled to its maximum value, $\left.\Delta x_{\max }\right)$ and membrane potential $V$, given by the following: $\Delta x / \Delta x_{\max }=\left(1+\exp \left(\left(V_{0.5}-V\right) / V_{\epsilon}\right)\right)^{-1}$, where $V_{0.5}$ is the membrane potential for half-activation, and $V_{\epsilon}$ is a slope factor. The values of $V_{0.5}$ and $V_{\epsilon}$ were -9 and $29 \mathrm{mV}$, respectively, for chloride and +65 and $28 \mathrm{mV}$ for sulfate. The fits indicate a similar voltage sensitivity (slope factor) of the process for the two anions, but with activation in sulfate being shifted to more positive potentials. These results show similarity to the voltage dependence of the somatic contractions reported later for isolated rat outer hair cells.

\section{Variations of hair bundle movements with age}

During the second postnatal week, the peripheral auditory system in rats matures to culminate in the onset of hearing at approximately P12. A component of this maturation, occurring between $\mathrm{P} 6$ and $\mathrm{P} 12$, is the acquisition by the OHCs of somatic motility attributable to increased expression of prestin (Belyantseva et al., 2000). In contrast, the MET channels are fully functional over this period (Kennedy et al., 2003), and the principal factor that affects mechanotransduction is the development of an endocochlear potential (Bosher and Warren, 1971). The maximum hair bundle movement increased monotonically with age from P6 to P11 (Fig. 5A). Because of our inability to isolate cochlear segments without visible damage to the organ of Corti (often swelling or loss of refractility in the OHC soma but most prominently breaks in or disorganization of the hair bundles), it was not possible to investigate systematically hair bundle movements in older "hearing" animals. However, two measurements at P14 were consistent with this pattern of development. There was, however, no evidence for an increase in the magnitude of the MET current over the same period (Fig. $5 B$ ). Indeed, there was a trend in the opposite direction, but this is most likely an artifact of the increased difficulty of cochlear isolation. [The mean currents for P6-P11 animals, of 0.5-0.8 $\mathrm{nA}$, are within the range of those reported previously at this apical cochlear location (Kennedy et al., 2003).] The results are therefore consistent with the development of somatic motility and not with any direct upregulation of the MET conductance.

\section{Contribution of the somatic motor to hair bundle movements}

Although the effect of postnatal age on depolarization-evoked hair bundle movements indirectly suggests a role for the somatic motor, two lines of evidence directly support its involvement in our measured hair bundle motion. OHC motility and the associated nonlinear capacitance are known to be blocked by Na salicylate (Shehata et al. $1991)$ with half-inhibition $\left(K_{\mathrm{I}}\right)$ in the millimolar range $\left[K_{\mathrm{I}}\right.$ of 4 $\mathrm{mm}$ (Tunstall et al., 1995); $K_{\mathrm{I}}$ of $1.6 \mathrm{~mm}$ (Kakehata and SantosSacchi 1996)]. External perfusion with $10 \mathrm{~mm}$ Na salicylate produced a reduction in the hair bundle displacement and abolition of the nonlinear capacitance seen in the current transients at the start and end of the voltage step (Fig. 6). Onset of block occurred over $10 \mathrm{~min}$, consistent with the notion that the ion penetrates the cells and acts at the intracellular surface. It was difficult to maintain the necessary degree of stability, especially for the optical recordings, over this period. Nevertheless, results in three cells (P7, P10, and P11), all with similar large initial movements (mean amplitude of $42 \mathrm{~nm}$ ), showed a mean fractional reduction of $0.68 \pm 0.05$. In these experiments, a sulfate-based intracellular solution was used, which might be expected to potentiate the effects of the salicylate that is thought to act by competing at the anion binding site on the prestin (Oliver et al., 2001). In all cases, the block was irreversible, and some cell deterioration occurred with an increase in the leak current. The slow onset of block and the lack of reversibility, in contrast to the effects on dissociated OHCs (Tunstall et al., 1995; Kakehata and Santos-Sacchi 1996), may be partly attributable to the limited access on the basolateral surface of the hair cells in the intact epithelium.

Exposure to salicylate over this period of time was also associated with $\sim 40 \%$ reduction in the maximum amplitude of the MET current (ratio of MET current in salicylate relative to control, $0.6 \pm 0.09 ; n=4$ ). This reduction was accompanied by a slowing of adaptation and abolition of the nonlinear capacitance (Fig. 6B). Figure 7 shows the effects of salicylate application in cells with both chloride-based and sulfate-based intracellular media, the latter being the same cell whose depolarization-evoked bundle motion is depicted in Figure 6. However, it would be unwise to conclude that salicylate has a direct effect on the MET channels because the reduction in current may have resulted partly from a side effect, such as a drop in intracellular $\mathrm{pH}$. Salicylate has been shown to acidify the cytoplasm (Tunstall et al., 1995), and an increase in intracellular $\mathrm{H}^{+}$ions may have caused 
A

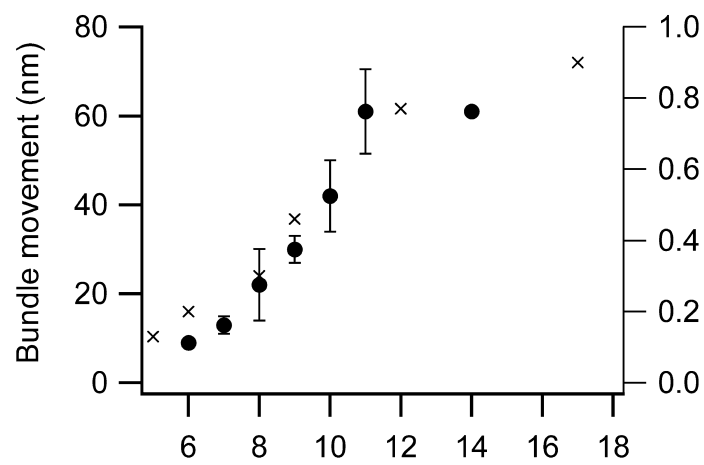

B

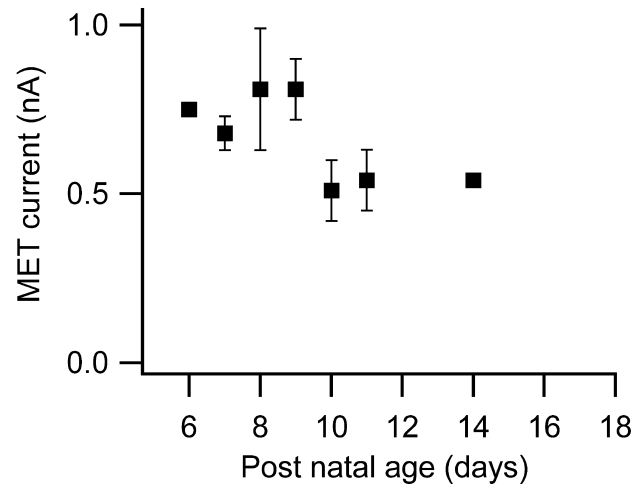

Figure 5. Effects of postnatal development on bundle movements and MET currents. $\boldsymbol{A}$, Maximum hair bundle motion for depolarization to $+80 \mathrm{mV}$ increases with postnatal age of the rat (circles). Superimposed on the results is the development of somatic electromotility with postnatal age of rat (crosses: normalized data taken from Belyantseva et al., 2000, their Fig. 4) referred to the right axis. Note that, according to their normalization, maximum somatic motility is not achieved until after P20 and, at P17, is 0.9 of the adult. $B$, Peak mechanotransducer currents at $-80 \mathrm{mV}$ holding potential changes little over the same developmental period. Each point is the mean \pm SEM of two to nine measurements. Both measurements at P14 were from hearing animals.
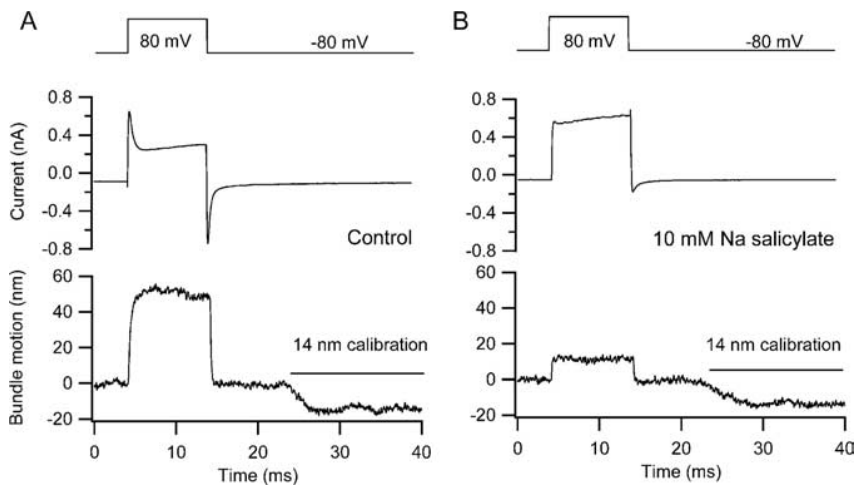

Figure 6. Effects of Na salicylate on hair bundle movements. $\boldsymbol{A}$, Membrane current and bundle movement for depolarization to $+80 \mathrm{mV}$ before applying Na salicylate. $\boldsymbol{B}$, Membrane current and bundle movement for depolarization to $+80 \mathrm{mV} 9$ min after starting perfusion with $10 \mathrm{~mm}$ Na salicylate. No recovery was obtained on return to control solution. Na salicylate blocks the somatic motor, as indicated by the disappearance of the nonlinear capacitance reflected by the current transients at the onset and termination of the voltage step. $\mathrm{P} 11$ rat, $\mathrm{CS}_{2} \mathrm{SO}_{4}$ intracellular, maximum MET current of $0.40 \mathrm{nA}$.

some block of the channels. In contrast to the present results, measurements on turtle auditory hair cells indicated that $10 \mathrm{mM}$ salicylate does not substantially diminish the amplitude of the MET currents (LeBlanc and Ricci, 2003).

A second type of experiment to address the mechanism of the bundle movements is to look for concomitant motion at the top
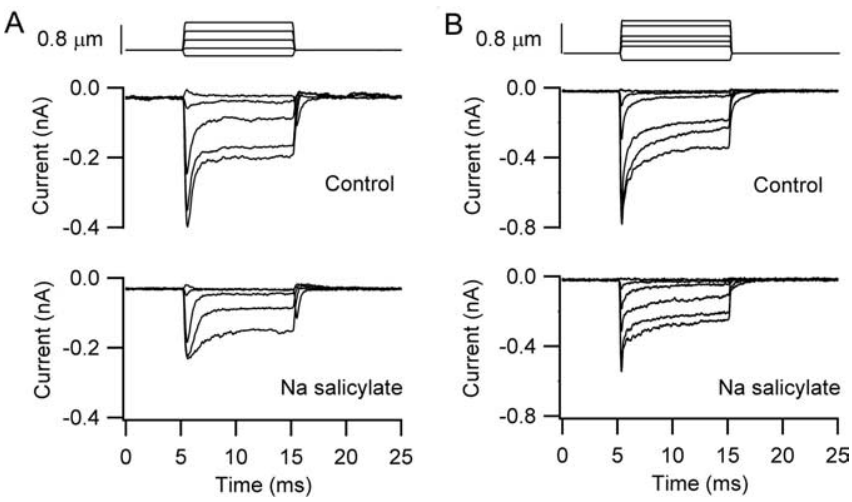

Figure 7. Effects of Na salicylate on mechanotransducer currents. $A, M E T$ currents before and $15 \mathrm{~min}$ after $10 \mathrm{~mm}$ Na salicylate perfusion for the cell of Figure 6. The test MET currents were acquired after the records in Figure $6 B$ when the nonlinear capacitance in response to depolarizing voltage steps had disappeared. $\mathrm{P} 11$ rat, $\mathrm{Cs}_{2} \mathrm{SO}_{4}$ intracellular, maximum MET current of 0.40 nA. $\boldsymbol{B}, \mathrm{MET}$ currents before and $30 \mathrm{~min}$ after $10 \mathrm{~mm}$ Na salicylate perfusion. The test MET currents were acquired once the nonlinear capacitance had disappeared (data not shown). P7 rat, CsCl intracellular, maximum MET current of $0.73 \mathrm{nA}$.

of the cell. If the voltage-evoked hair bundle movements originate solely from changes in MET channel gating and bundle compliance, then each bundle should move independently of its neighbors. However, if a component of the bundle motion results from either tilting of the cuticular plate or contraction of the cell body, then the motion should be transmitted to adjacent cells that, in the intact epithelium, are mechanically coupled to the cell being stimulated. The contrast (e.g., in the junction with the neighboring Deiters cell phalangeal processes) was inadequate to directly image the cellular apex. However, an alternative approach was to examine the motion of adjacent hair bundles. Because they possessed similar orientation and light piping, we chose to look at other OHC hair bundles along the same row, usually the first row. Surprisingly, we found some movement of the hair bundle of the cell next to the one that was being depolarized (Fig. 8). In the example depicted, hair bundle 2 moved by approximately one-third that of hair bundle 1 , attached to the cell being depolarized. In five experiments, the mean deflection of the adjacent hair bundle along the same row was $0.29 \pm 0.1$. In none of these experiments was any movement detected in hair bundle 3 , the next but one along the same row. These results suggest that depolarization causes motion of the reticular lamina that is transmitted to the adjacent cell. The length constant for propagation of the mechanical response along the organ of Corti is approximately one hair cell width, $\sim 10 \mu \mathrm{m}$. Mechanical coupling between OHCs has been observed previously in groups of isolated hair cells by (Zhao and Santos-Sacchi, 1999), but the polarity of the transmission was different in those experiments, stimulation of one OHC causing motion of opposite polarity in an adjacent cell.

\section{Somatic contractility in solitary hair cells}

A series of measurements were made on solitary OHCs to test directly the effects on somatic contractility of the manipulations used in studying hair bundle movements. The hair cells were obtained by enzymatic dissociation of the organ of Corti, and recordings were made with either chloride- or sulfate-containing intracellular solutions. Depolarization using a chloride-based intracellular solution evoked rapid somatic contractions (Ashmore, 1987), with a maximum factional shortening of $0.043 \pm$ 0.01 in 11 cells of mean length $32.5 \pm 1.7 \mu \mathrm{m}$. The mean change 

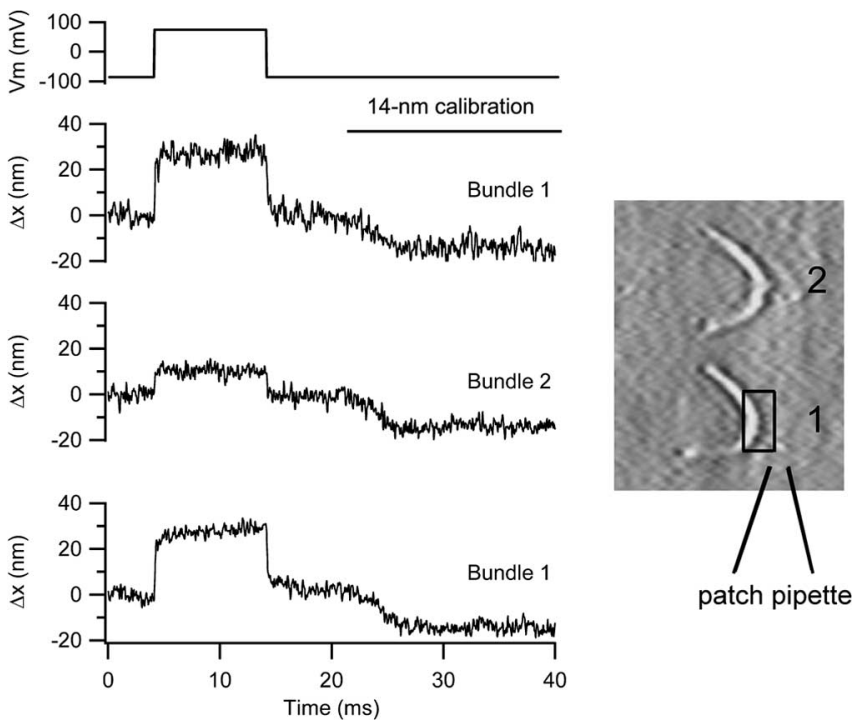

Figure 8. Depolarization evokes motion of adjacent hair bundle. Bundle movements when the photodiode was positioned on the bundle of the cell being depolarized (trace 1, bundle 1). Photodiode was positioned on the bundle of the next cell along in the row (trace 2, bundle 2). $0 \mathrm{n}$ returning the photodiode to bundle 1, (trace 3), the same size of response was elicited. For each movement record, the negative excursion at the end of the trace is the $14 \mathrm{~nm}$ calibration. On the right is shown two hair bundles, the location of the patch pipette, and the photodiode pair superimposed on bundle 1. P10 rat, $\mathrm{CSCl}$ intracellular, maximum MET current of $1 \mathrm{nA}$.

in cell length was $1.4 \mu \mathrm{m}$ in P10-P16 rats. The voltage-activation relationship with the chloride-based intracellular solution (Fig. 9) could be fit with a Boltzmann relationship (equation in Materials and Methods) with a $V_{0.5}$ of $-47 \pm 4 \mathrm{mV}(n=11)$. In agreement with previous work (Kakehata and Santos-Sacchi, 1996), $10 \mathrm{~mm}$ salicylate substantially reduced the somatic contractions (maximum length change: $0.74 \mu \mathrm{m}$ control, $0.12 \mu \mathrm{m} 9$ min after salicylate application, and $0.37 \mu \mathrm{m}$ for recovery). When sulfate was used as the intracellular anion, the activation relationship measured in other cells was shifted $>120 \mathrm{mV}$ positive, with a $V_{0.5}>79 \mathrm{mV}(n=5)$. In this sulfate solution, a maximum factional shortening of $0.023 \pm 0.008$ was measured in the five cells of mean length $33.4 \pm 0.9 \mu \mathrm{m}$. In three of these recordings, replacement of extracellular chloride with gluconate did not further affect the amplitude of the movements. The maximum shortening may have been underestimated with the sulfate-based intracellular solution because, in most cases, a clear saturation of the movement was not achieved (Fig. 9). This implies that activation of the prestin motor is equally supported with a sulfatebased (chloride-free) medium but that the activation range is translated to positive membrane potentials. This conclusion accords with Rybalchenko and Santos-Sacchi (2003) but disagrees with Oliver et al. (2001) who observed no prestin activation (inferred from nonlinear capacitance measurements) when internal chloride was replaced with sulfate.

A second point addressed in the solitary hair cell measurements was whether DHS affected the contractility. After 5-8 min perfusion, there was no major reduction in the amplitude of the depolarization-evoked shortening (Fig. 9). The maximum length change in $0.2 \mathrm{~mm}$ DHS compared with the control was $1.06 \pm$ 0.03 in seven cells. Sometimes a small positive shift in the activation curve was seen with a mean $V_{0.5}$ of $-40.0 \pm 5.5 \mathrm{mV}(n=7)$. There was no evidence for a larger reversible reduction in motility as found with the hair bundle movements (Fig. 1).
A

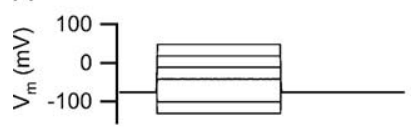

B
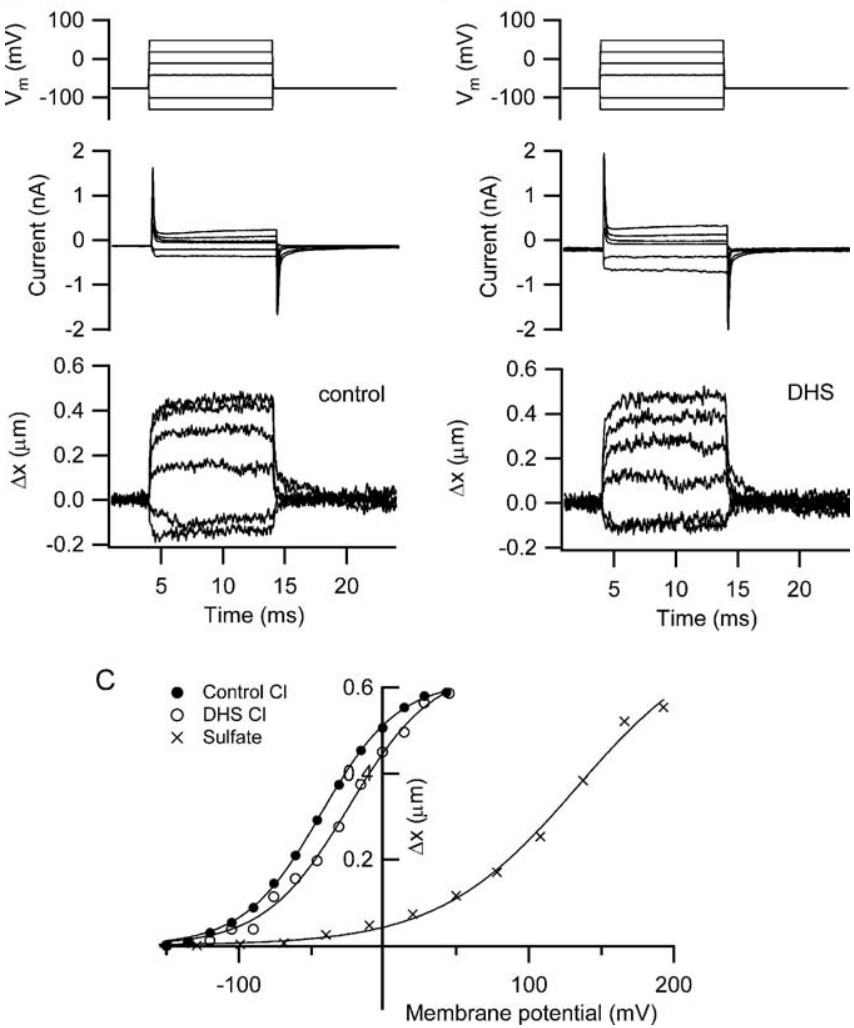

Figure 9. Somatic contractions measured in rat isolated hair cells. $A$, Membrane currents (middle traces) and changes in length ( $\Delta x$, bottom traces) in an outer hair cell in response to a series of depolarizing and hyperpolarizing voltage steps. Intracellular solution contained CsCl. $B$, Same measurements made 5 min after starting perfusion with $0.2 \mathrm{~mm}$ DHS, indicating no effect of the antibiotic on maximum movements or modest effect on the currents. $C$, Dependence of length change, $\Delta x$, on membrane potential for the responses in $\boldsymbol{A}$ (filled circles) and $\boldsymbol{B}$ (open circles). Also shown is the variation of length change with membrane potential in another outer hair cell recorded with an intracellular solution containing $\mathrm{CS}_{2} \mathrm{SO}_{4}$ and gluconate as the principal external anion. Smooth curves are fits to the following: $\Delta x / \Delta x_{\max }=\left(1+\exp \left(\left(V_{0.5}\right.\right.\right.$ $\left.\left.-V) / V_{\epsilon}\right)\right)^{-1}$, where $V_{0.5}$ and $V_{\epsilon}$ were -43 and $27 \mathrm{mV}$, respectively, for control chloride, -26 and $29 \mathrm{mV}$ in the presence of DHS, and +133 and $48 \mathrm{mV}$ for sulfate. Outer hair cells isolated from a $\mathrm{P} 11$ rat (DHS experiment) and a $\mathrm{P} 13$ rat $\left(\mathrm{CS}_{2} \mathrm{SO}_{4}\right.$ experiment).

\section{Discussion}

Hair bundle motion mediated by somatic motility

We have observed depolarization-evoked movements of hair bundles in neonatal rat OHCs both before and, in two P14 animals, after the onset of hearing. All cells studied displayed mechanotransduction, and the displacement was always in the positive direction with amplitude of several tens of nanometers. Two lines of evidence strongly argue that the movements were partly driven by somatic contractions thought to be mediated by prestin: (1) a concomitant motion of the hair bundle of the cell adjacent to the one being polarized; (2) at least a 70\% reduction in the displacement amplitude by Na salicylate, a blocker of somatic contractility (Shehata et al., 1991; Kakehata and Santos-Sacchi, 1996). Salicylate is not a completely specific agent to use on auditory hair cells because it has been has found to elevate the sound threshold at the characteristic frequency of pigeon auditory nerve fibers (Shehata-Dieler et al., 1994) and to suppress otoacoustic emissions in lizards (Stewart and Hudspeth, 2000). Hair cells in neither pigeon nor lizard possess prestin-driven somatic contractility, and both effects might stem from an inhibition of the MET channels. We observed an $\sim 40 \%$ reduction in the maximum MET current in the rat, but some of this loss may have resulted 
from deterioration in the preparation during the prolonged exposure time. Salicylate has been shown to partially block neuronal L-type $\mathrm{Ca}^{2+}$ channels (Liu et al., 2005) and may have other unknown effects on hair cell function by virtue of reduction in intracellular $\mathrm{pH}$. Two additional observations provided circumstantial support for the contribution of somatic contractility to hair bundle movements. First, the size of the movements increased with postnatal age (Fig. 5) with a time course that paralleled the acquisition of somatic contractility in the rat (Oliver and Fakler, 1999; Belyantseva et al., 2000; Beurg et al., 2001). Thus, both increased between P6 and P11 and were close to maximal at the onset of hearing. Second, the range of membrane potentials for eliciting the movements depended on whether chloride or sulfate was used as an intracellular anion (Fig. 4) in much the same manner as did somatic contractility (Fig. 9) (Rybalchenko and Santos-Sacchi, 2003). However, there were quantitative differences between the anion effects on hair bundle motion and on somatic contractility. Replacement of intracellular chloride by sulfate produced a smaller positive shift with no change in slope for the bundle motion (Fig. 4) compared with somatic contractility (Fig. 9C). This suggests that the underlying motor mechanisms are not identical and that hair bundle motility may involve processes other than somatic contractility.

\section{Hair bundle motion attributable to MET channel gating}

Although the weight of evidence indicates that somatic contractility primarily underlies the hair bundle motion elicited by depolarization, three results support a contribution from the MET channels and the hair bundle motor. These are that the movements were partly suppressed by dihydrostreptomycin, a blocker of the MET channels, and by BAPTA, which abolishes transduction by severing the tip links. They were also enhanced by lowering extracellular $\mathrm{Ca}^{2+}$. Reduced $\mathrm{Ca}^{2+}$ is known to increase the probability of opening of the MET channels and will cause a negative shift in the $\mathrm{Ca}^{2+}$ equilibrium potential, enabling depolarizing voltage steps to more effectively open the MET channels. The effect of $\mathrm{Ca}^{2+}$ is opposite to that expected for somatic contractility, which is increased by raising rather than lowering the $\mathrm{Ca}^{2+}$ (Frolenkov et al., 2000; Beurg et al., 2001). Positive hair bundle movements, enhanced by lowering $\mathrm{Ca}^{2+}$ and blocked by DHS, have been seen previously in response to depolarization of turtle auditory hair cells (Ricci et al., 2000). These depolarizationevoked movements were between 10 and $75 \mathrm{~nm}$, a range similar to that observed in rat OHCs. The origin of such bundle movements can be explained in terms of the gating spring model for MET channel activation (Howard and Hudspeth, 1988) in which channel opening decreases hair bundle stiffness. Depolarizations positive to $0 \mathrm{mV}$ should reduce intracellular $\mathrm{Ca}^{2+}$, which shifts the activation curve to less positive displacements, thus increasing the proportion of channels open at rest. This will decrease hair bundle stiffness and therefore, with no applied force, cause the bundle to move further in the positive direction (Ricci et al., 2000, their Fig. 12B). The notion of "gating compliance" was derived on the basis of nonlinearity in the force-displacement relationship of the hair bundle in nonmammalian vertebrates (Howard and Hudspeth, 1988; Ricci et al., 2002). However, manifestations of gating compliance have also been seen in mammalian OHCs (Russell et al., 1992; van Netten and Kros, 2000). It is therefore not unreasonable to expect active hair bundle motion in mammals similar to nonmammals.

Our results are similar in several respects to recently published work (Jia and He, 2005), in which large hair bundle movements were elicited by depolarization of individual $\mathrm{OHCs}$ in isolated cochleas. However, there are two crucial differences that lead to an alternative conclusion about the underlying mechanism. First, they found no connection to MET channel gating, either attenuation by block of the MET channels or augmentation by lowering extracellular $\mathrm{Ca}^{2+}$. However, they provide no evidence that fast adaptation was present in their OHCs, especially in the older, up to $\mathrm{P} 35$, animals. It is possible that cells in preparations from older animals rapidly become calcium loaded, which would abolish the effects of depolarization on MET channel gating and its susceptibility to altering extracellular calcium. Second, the size of the bundle movements they observed was comparable with that of isolated OHCs when depolarized. It is unclear how an equivalent radial motion is caused by somatic contractions of vertically oriented OHCs. An unavoidable conclusion is that movements of their OHCs were unhampered by cell attachments either within the organ of Corti or at the reticular lamina. This could only occur if the organ of Corti were disrupted by the recording electrode. In the face of such large movements attributable to unimpeded cellular contractions, it is not surprising that the contribution of the MET channels was not seen. We took special care to record several cells along from the point at which the electrode pierced the reticular lamina so as to preserve its structural integrity. Furthermore, our bundle movements were only $1 / 10$ those of isolated cells, consistent with an intact reticular lamina whose stiffness limited the motion of the cell apex. Our measurements suggest a more complex mechanism for active hair bundle motion.

\section{Depolarization-evoked bundle motion occurs by two mechanisms}

If the hair bundle motion observed here were entirely a product of somatic contractility, then it is still small ( $80 \mathrm{~nm}$ maximum) compared with the length changes found in isolated OHCs $(\sim 1$ $\mu \mathrm{m})$ observed under similar conditions. Two factors might account for this discrepancy. First, longitudinal contractions of $\mathrm{OHCs}$ would not necessarily be converted into an equivalent radial motion of the cell apex (and hence of the hair bundle). To facilitate recordings and optimize light piping by the bundle, $\mathrm{OHCs}$ were tilted by no more than $20^{\circ}$ from the optical axis, bases more abneural than the apex (see Materials and Methods) so the radial motion attributable to longitudinal contractions would be small. Nevertheless, large radial movements of OHCs, possibly caused by tilting of the cuticular plate, have been seen previously in the intact organ of Corti (Reuter and Zenner, 1990). However, the electrical stimuli were applied across the whole epithelium, thus polarizing many cells. Second, if only a single OHC were depolarized, its motion would be restricted by attachments to neighboring cells and by the stiffness of the reticular lamina (assuming that most of the force developed by OHC shortening went into deforming the reticular lamina rather the basilar membrane) (Mammano and Ashmore, 1993). These mechanical limitations could account for the smaller motion of adjacent cells in the same row (Fig. 8).

Our measurements give no indication of the forces generated by each of the two processes (which may be important for assessing physiological relevance), but they do indicate that bundle motion arising from channel gating is of comparable magnitude with that of radial motion of the cell apex. How might these two components interact? The simplest view is to regard the stereociliary and somatic motors as independent, at least in voltage-clamped cells, in which case their motions should sum. However, this notion is not wholly consistent with the action of blocking agents DHS and salicylate. For 
animals of the same developmental age (P7-P11), DHS reduced bundle motion brought about by the channel motor on average by $72 \%$, whereas salicylate reduced motion on average by $68 \%$. If the motors were independent and the blockers specific, the reductions should sum to $100 \%$. So it may be that deflection of the stereocilia after stepping to a positive voltage signals in some way to the somatic motor, even when the membrane potential is constant. Because $\mathrm{Ca}^{2+}$ entering through MET channels would take several milliseconds to diffuse the length of the hair bundle, this type of signal seems too slow. A direct mechanical linkage, perhaps involving stretchsensitive channels in the cell body (Ding et al., 1991; Rybalchenko and Santos-Sacchi, 2003), might fulfill this role, but more experiments are needed to investigate possible mechanisms. In summary, our results demonstrate that electrical stimuli applied across the organ of Corti, which have been used to examine cochlear mechanics in both isolated (Mammano and Ashmore, 1993; Scherer and Gummer, 2004; Chan and Hudspeth, 2005; Jia and He, 2005) and intact (Xue et al., 1995; Nuttall et al., 1999) preparations, cannot be assumed to operate exclusively through effects on the OHC somatic or hair bundle motors but may involve a complex interaction between the two.

\section{References}

Ashmore JF (1987) A fast motile response in guinea-pig outer hair cells: the cellular basis of the cochlear amplifier. J Physiol (Lond) 388:323-347.

Ashmore JF (1989) Transducer motor coupling in cochlea outer hair cells. In: Cochlear mechanisms: structure, function and models (Wilson JP, Kemp DT, eds), pp 107-114. New York: Plenum.

Assad JA, Hacohen N, Corey DP (1989) Voltage dependence of adaptation and active bundle movement in bullfrog saccular hair cells. Proc Natl Acad Sci USA 86:2918-2922.

Assad JA, Shepherd GM, Corey DP (1991) Tip-link integrity and mechanical transduction in vertebrate hair cells. Neuron 7:985-994.

Belyantseva IA, Adler HJ, Curi R, Frolenkov GI, Kachar B (2000) Expression and localization of prestin and the sugar transporter GLUT-5 during development of electromotility in cochlear outer hair cells. J Neurosci 20:RC116(1-5).

Benser ME, Marquis RE, Hudspeth AJ (1996) Rapid, active hair bundle movements in hair cells from the bullfrog's sacculus. J Neurosci 16:5629-5643.

Beurg M, Bouleau Y, Dulon D (2001) The voltage-sensitive motor protein and the $\mathrm{Ca}^{2+}$ sensitive cytoskeleton in developing rat cochlear outer hair cells. Eur J Neurosci 14:1947-1952.

Bosher SK, Warren RL (1971) A study of the electrochemistry and osmotic relationships of the cochlear fluids in the neonatal rat at the time of development of the endocochlear potential. J Physiol (Lond) 212:739-761.

Bosher SK, Warren RL (1978) Very low calcium content of cochlear endolymph, an extracellular fluid. Nature 273:377-378.

Brownell WE, Bader CR, Bertrand D, de Ribaupierre Y (1985) Evoked mechanical responses of isolated cochlear outer hair cells. Science 227:194-196.

Chan DK, Hudspeth AJ (2005) $\mathrm{Ca}^{2+}$-current driven non-linear amplification by the mammalian cochlea in vitro. Nat Neurosci 8:149-155.

Crawford AC, Fettiplace R (1985) The mechanical properties of ciliary bundles of turtle cochlear hair cells. J Physiol (Lond) 364:359-379.

Crawford AC, Evans MG, Fettiplace R (1989) Activation and adaptation of transducer currents in turtle hair cells. J Physiol (Lond) 419:405-434.

Crawford AC, Evans MG, Fettiplace R (1991) The actions of calcium on the mechano-electrical transducer current of turtle hair cells. J Physiol (Lond) 434:369-398.

Dallos P (1992) The active cochlea. J Neurosci 12:4575-4585.

Ding JP, Salvi RJ, Sachs F (1991) Stretch-activated ion channels in guinea pig outer hair cells. Hear Res 56:19-28.

Fettiplace R, Ricci AJ (2003) Adaptation in auditory hair cells. Curr Opin Neurobiol 13:446-451.

Frolenkov GI, Mammano F, Belyantseva IA, Coling D, Kachar B (2000)
Two distinct $\mathrm{Ca}^{2+}$-dependent signaling pathways regulate the motor output of cochlear outer hair cells. J Neurosci 20:5940-5948.

Gillespie PG, Cyr JL (2004) Myosin-1c, the hair cell's adaptation motor. Annu Rev Physiol 66:521-545.

Howard J, Hudspeth AJ (1987) Mechanical relaxation of the hair bundle mediates adaptation in mechanoelectrical transduction by the bullfrog's saccular hair cell. Proc Natl Acad Sci USA 84:3064-3068.

Howard J, Hudspeth AJ (1988) Compliance of the hair bundle associated with gating of mechanoelectrical transduction channels in the bullfrog's saccular hair cell. Neuron 1:189-199.

Jia S, He DZ (2005) Motility-associated hair-bundle motion in mammalian outer hair cells. Nat Neurosci 8:1028-1034.

Kakehata S, Santos-Sacchi J (1996) Effects of salicylate and lanthanides on outer hair cell motility and associated gating charge. J Neurosci 16:4881-4889.

Kennedy HJ, Evans MG, Crawford AC, Fettiplace R (2003) Fast adaptation of mechanoelectrical transducer channels in mammalian cochlear hair cells. Nat Neurosci 6:832-836.

Kennedy HJ, Crawford AC, Fettiplace R (2005) Force generation by mammalian hair bundles supports a role in cochlear amplification. Nature 433:880-883.

Kroese AB, Das A, Hudspeth AJ (1989) Blockage of the transduction channels of hair cells in the bullfrog's sacculus by aminoglycoside antibiotics. Hear Res 37:203-217.

Kros CJ, Rüsch A, Richardson GP (1992) Mechano-electrical transducer currents in hair cells of the cultured neonatal mouse cochlea. Proc R Soc Lond B Biol Sci 249:185-193.

LeBlanc CS, Ricci AJ (2003) Salicylate affects mechano-electric transduction. Assoc Res Otolaryngol Abstr 26:11.

Liberman MC, Gao J, He DZZ, Wu X, Jia S, Zuo J (2003) Prestin is required for electromotility of the outer hair cell and for the cochlear amplifier. Nature 419:300-304.

Liu Y, Li X, Ma C, Liu J, Lu H (2005) Salicylate blocks L-type calcium channels in rat inferior colliculus neurons. Hear Res 205:271-276.

Mammano F, Ashmore JF (1993) Reverse transduction measured in an isolated cochlea by laser Michelson interferometry. Nature 365:838-841.

Martin P, Hudspeth AJ (1999) Active hair-bundle movements can amplify a hair cell's response to oscillatory mechanical stimuli. Proc Natl Acad Sci USA 96:14306-14311.

Müller M (1991) Frequency representation in the rat cochlea. Hear Res 51:247-254.

Nuttall AL, Guo M, Ren T (1999) The radial pattern of basilar membrane motion evoked by electric stimulation of the cochlea. Hear Res 131:39-46.

Oliver D, Fakler B (1999) Expression density and functional characteristics of the outer hair cell motor protein are regulated during postnatal development in rat. J Physiol (Lond) 519:791-800.

Oliver D, He DZ, Klocker N, Ludwig J, Schulte U, Waldegger S, Ruppersberg JP, Dallos P, Fakler B (2001) Intracellular anions as the voltage sensor of prestin, the outer hair cell motor protein. Science 292:2340-2343.

Reuter G, Zenner H-P (1990) Active radial and transverse motile responses of outer hair cells in the organ of Corti. Hear Res 43:219-230.

Ricci A (2002) Differences in mechano-transducer channel kinetics underlie tonotopic distribution of fast adaptation in auditory hair cells. J Neurophysiol 87:1738-1748.

Ricci AJ, Crawford AC, Fettiplace R (2000) Active hair bundle motion linked to fast transducer adaptation in auditory hair cells. J Neurosci 20:7131-7142.

Ricci AJ, Crawford AC, Fettiplace R (2002) Mechanisms of active hair bundle motion in auditory hair cells. J Neurosci 22:44-52.

Ricci AJ, Crawford AC, Fettiplace R (2003) Tonotopic variation in the conductance of the hair cell mechanotransducer channel. Neuron 40:983-990.

Roth B, Bruns V (1992) Postnatal development of the rat organ of Corti. II. Hair cell receptors and their supporting elements. Anat Embryol 185:571-581.

Russell IJ, Kössl M, Richardson GP (1992) Nonlinear mechanical responses of mouse cochlear hair bundles. Proc R Soc Lond B Biol Sci 250:217-227.

Rybalchenko V, Santos-Sacchi J (2003) $\mathrm{Cl}^{-}$flux through a non-selective, stretch-sensitive conductance influences the outer hair cell motor of the guinea pig. J Physiol (Lond) 547:873-891. 
Santos-Sacchi J (1991) Reversible inhibition of voltage-dependent outer hair cell motility and capacitance. J Neurosci 11:3096-3110.

Scherer MP, Gummer AW (2004) Vibration pattern of the organ of Corti up to $50 \mathrm{kHz}$ : evidence for resonant electromechanical force. Proc Natl Acad Sci USA 101:17652-17657.

Shehata WE, Brownell WE, Dieler R (1991) Effects of salicylate on shape, electromotility and membrane characteristics of isolated outer hair cells from guinea pig cochlea. Acta Otolaryngol 111:707-718.

Shehata-Dieler WE, Richter CP, Dieler R, Klinke R (1994) Effects of endolymphatic and perilymphatic applications of salicylate in the pigeon. I. Single fiber activity and cochlear potentials. Hear Res 74:77-84.

Stewart CE, Hudspeth AJ (2000) Effects of salicylates and aminoglycosides on spontaneous otoacoustic emissions in the Tokay gecko. Proc Natl Acad Sci USA 97:454-459.
Tucker TR, Fettiplace R (1996) Monitoring calcium in turtle hair cells with a calcium-activated potassium channel. J Physiol (Lond) 494:613-626.

Tunstall MJ, Gale JE, Ashmore JF (1995) Action of salicylate on membrane capacitance of outer hair cells from the guinea-pig cochlea. J Physiol (Lond) 485:739-752.

van Netten SM, Kros CJ (2000) Gating energies and forces of the mammalian hair cell transducer channel and related hair bundle mechanics. Proc R Soc Lond B Biol Sci 267:1915-1923.

Xue S, Mountain DC, Hubbard AE (1995) Electrically evoked basilar membrane motion. J Acoust Soc Am 97:3030-3041.

Zhao HB, Santos-Sacchi J (1999) Auditory collusion and a coupled couple of outer hair cells. Nature 399:359-362.

Zheng J, Shen W, He DZ, Long KB, Madison LD, Dallos P (2000) Prestin is the motor protein of cochlear outer hair cells. Nature 405:149-155. 